\title{
Letter from . . . Chicago
}

\section{When to stop treatment}

\author{
GEORGE DUNEA
}

\begin{abstract}
"How are you John?" asks the nurse, bending tenderly over a comatose man in the intensive care unit. As she pulls up his eyelids the eyes deviate to the left, the face twitches, the right leg jerks spasmodically. Chronically aplastic and paralysed, he had come from a nursing home with high fever, unrecordable blood pressure, and necrotic bed sores. He needs powerful antibiotics for his Gram negative septicaemia and dopamine to maintain his circulation, while a rising blood urea concentration has inevitably brought up the question of dialysis. Already his shrivelled body looks like a corpse, the chest hyperexpanded but immobile, the collapsed abdomen moving in concert with the respirator. But within a few days the fever abates and the blood pressure stabilises. Later a deep festering sore develops on the buttocks, the toes become gangrenous, and one leg has to be amputated. Then four months go by and he is still comatose, still attached to a respirator that nobody would think of disconnecting.
\end{abstract}

It is cases like this that are so troubling, and there are so many of them. Already one fifth of Medicare's annual budget of $\$ 49$ billion is being spent on patients in their last few months of life; and as the cost of caring for a patient with terminal cancer now exceeds $\$ 16000$ many people are beginning to question the "do everything approach." Thus in a recent survey $71 \%$ of people said that the life support systems of hopelessly ill patients should be unplugged. In another poll more than one half of respondents thought that doctors should be allowed to comply with requests for mercy killing. Meanwhile, as the doctors are continually faced with such difficult problems, the courts send out ambiguous signals, sometimes raising more questions than they answer.

In the years that have elapsed since the debate over Karen Quinlan many other cases in which no agreement could be reached have ended up in the adversarial atmosphere of the courts. Competent patients have had to appeal to the law to have respirators or dialysis treatments stopped. Relatives of comatose patients have likewise had to petition the courts to prevail on nervous hospitals or overenthusiastic doctors to discontinue intravenous fluids or tube feedings. In one controversial case a judge ordered blood transfusions against the family's wishes on the grounds that a demented patient's preference could not be determined. Last year, in Illinois, overzealous local officials prosecuted the parents of Siamese twins for allegedly requesting that their infants should not be fed; and more recently, in Los Angeles, two doctors were prosecuted for murder when in concurrence with relatives' wishes they removed the respirator from an unconscious patient and then, when he remained in coma, stopped tube feedings. In most other hospitals fears of prosecution result in

Cook County Hospital, Chicago, Illinois, USA GEORGE DUNEA, FRCP, FRCPED, attending physician the widespread use of aggressive treatment when the condition is hopeless, as shown by three quarters of all doctors routinely ordering intravenous fluids for dying patients. ${ }^{1}$ Yet almost everybody appreciates the futility of such heroic efforts-and then we read how even the occasional survivors from prolonged coma lead vegetative lives, blind, paralysed, in constant pain. Relatives too may be driven to desperation. When doctors in Texas insisted on continuing to feed a permanently unconscious man the younger son shot his father through the head to put him out of his misery. ${ }^{23}$

So our progress in therapeutics brings new ethical dilemmas each day, as even the distinctions between active and passive actions have become blurred; and what once was extraordinary treatment has become commonplace in a world where respirators are ubiquitous and the use of powerful antibiotics the expected norm. Nothing extraordinary, then, in ordering yet another course of antibiotics for an aphasic, paralysed 83 year old woman who has again developed pneumonia. Perhaps the only unusual aspect of that case, recently the subject of a sensitive editorial, ${ }^{4}$ was that the doctor, instead of ordering an antibiotic on the telephone and going back to sleep, got up at $3 \mathrm{am}$, went to the nursing home to examine the patient, woke up the $x$ ray technician, and even ordered an immediate sputum culture. But his musings on the way home about these rarely discussed ethical dilemmas are worth quoting: "The problem is simply too difficult for me as a single human being to face ... how can I make a decision about the quality of life? How do I know what the patient would want? The time has come that we publicly examine our role in these situations, offered each other some guidelines, and came to some consensus about our responsibility.",

\section{Attempt to establish guidelines}

One such attempt to begin a dialogue, reach a consensus, or at least establish some guidelines is reflected in this year's report by the President's Commission for the Study of Ethical Problems in Medicine. ${ }^{5}$ Established as an 11 member body by the Carter administration in 1979, and later reinforced by eight appointees of President Reagan's, the commission was chaired by a prominent lawyer, himself a victim of chronic leukaemia. ${ }^{6}$ After several years of hearings and deliberations the commission concluded its work with a series of publications on informed consent, patient doctor relationships, and the ethics of providing access to medical care. As a natural outgrowth of its studies, though not part of its original mandate, it published in March a monograph on stopping life sustaining treatment. ${ }^{5}$ One of its conclusions, emphasised in the introduction, was that true ethical difficulties were less common than is widely believed, that difficulties often stem from a misunderstanding of the dictates of ethics and law, and that neither civil nor criminal law prevents doctors from reaching sound decisions on when to stop treatment.

The report addresses a wide variety of issues against the 
background of a pleuralistic society in which "perspectives on death are as numerous as the philosophies and religions that gave them birth" and in which some $80 \%$ of all deaths now occur in hospitals and nursing homes. While decrying the disservice of "empty rhetoric" exemplified by such slogans as "death with dignity" or "the right to life," the report emphasises that much can be done to improve the physical and emotional state of patients who are dying. At all points, however, the goal of securing a patient's health and wellbeing must be pursued with recognition that a competent person has a right to make his own decisions, and that a process of collaborating and sharing information and responsibility between doctor and patient gives best results.

Of particular interest in this report is a detailed analysis of the elements of making correct ethical decisions and of the validity of certain widely used traditional moral distinctions. These are often considered in opposing categories: acting versus omitting to act, failing to initiate treatment versus discontinuing it, and ordinary versus extraordinary forms of treatment. The commission holds that in general these distinctions do not necessarily determine by themselves what is morally acceptable. Yet they may frequently provide the practitioner with a useful rule of thumb, by separating cases that probably deserve more scrutiny from those that are likely not to need it. Thus doctors may not actively kill but should usually honour treatment refusals by dying patients. They may use powerful analgesics even if this should result in an earlier death. Not initiating a certain treatment has the same moral implications as stopping it later and, though seeming to be legally safer, it might result in some patients being deprived of the benefits of treatment. Yet this would be unfortunate, because nothing in the law makes stopping treatment a more serious legal issue than not starting it.

On the problem of ordinary versus extraordinary measures the report traces the origins of this concept to mediaeval Catholic theology but holds that considerations of usefulness and burdensomeness to an individual offer a better means of analysing the alternatives. Throughout its report the commission concedes that life abounds with ambiguous cases but emphasises that the law does not prevent doctors from making ethically sound decisions, and that it certainly does not force patients to undergo procedures that would increase their suffering. Neither blood transfusions, nor antibiotics, nor intravenous fluids are universally mandatory, but, it is again emphasised, the decision to withhold one form of treatment does not constitute grounds for withdrawing all care-and indeed an entire appendix is devoted to the details of supportive care for the dying patient.

\section{Right of competent patients}

To summarise the main findings, then, the commission upholds the right of competent patients to decide for themselves what treatment they wish to accept or refuse, even if the latter should lead to an earlier death. Doctors should maintain a presumption in favour of sustaining life but may properly refuse options that violate their conscience, though in doing so they may not abandon the patient. Institutions or society may justifiably restrict options on grounds of cost, but in America this should not be done forcefully because there are many less painful measures that could save billions of dollars. Patients should be informed of available alternatives adequately and with as little bias as possible, and provisions should be made for the designation of surrogates, for "living wills," and for valid powers of attorney giving advance directions. Family members or appointed surrogates should decide for mentally incompetent patients, acting so as to uphold their best interests. Institutions should have explicit written guidelines on how decisions are to be made and implemented.

Most decisions should be made jointly by the relatives (or surrogates) and the doctor, supported by consultants or experts as needed. Hospital ethics committees, consisting of doctors and lay people, should spell out acceptable procedures and adjudicate when no agreement can be reached. More studies are needed to evaluate the effectiveness of such committees and determine if their role should be to confirm the diagnosis and prognosis, formulate guidelines, review decisions retrospectively, or make decisions themselves. Only rarely should cases be referred to outside courts because judicial review is costly, time consuming, disruptive of care, invasive of privacy, and often leads to an adversarial state of affairs and rarely an improvement on earlier decisions. So that, although some courts, especially in Massachusetts, have espoused an active role for the judiciary, experience suggests that the judges, lacking in understanding of the medical aspects, often simply defer to the opinion of the treating doctors.

Similar procedures are recommended for patients who are "brain dead"- a condition for which reliable diagnostic criteria are now available-and for patients in a persistent vegetative state, who rarely recover and who generally have only a "limited interest" in continuing treatment. Institutions should also establish explicit policies for cardiopulmonary resuscitation, requiring that "do not resuscitate" orders be confirmed in writing and spelling out who has the authority to write such orders or stop a resuscitation effort in progress. Doctors should maintain a presumption in favour of resuscitation should unexpected cardiac arrest occur. When cardiac arrest is likely the possibility might be discussed with the patients, the relative, or the surrogate, and persistent disagreements might on occasion be referred to an ethics committee. Again, an order not to resuscitate does not mean that other treatments should be withdrawn.

In general the report was well received. Its conclusions, though often tentative, will serve to open a dialogue on a sensitive topic and should eventually improve the climate in which these difficult decisions must be made. Already several newspapers have published extensive editorials on the ethical and political dilemmas resulting from our increased ability to postpone death. Thus the Chicago Tribune commented that, whereas the United States spent $10 \%$ of its gross national product on medical care, Great Britain has kept the cost down to $5.5 \%$, in part by making painful decisions and limiting certain expensive forms of treatment, such as dialysis for the aged or operations on advanced cases of spina bifida. Other editors commented that we are prisoners in a moral vacuum, and that a debate on these issues may be agonising but is inescapable. As a first step, the report is clearly an important one. If nothing else, much could be said for upholding properly reached decisions and removing the ever present fear of litigation by the setting up of institutional ethics committees. Additional help is already coming from the state legislatures, as shown by a recent Illinois law recognising and defining permanent loss of consciousness or "brain death." There is also a great need to spell out procedures for the care of premature or severely handicapped infants, an issue that recently caused considerable controversy, as will be reported in the next letter.

\section{References}

${ }^{1}$ Micetich KC, Steinecker PH, Thomasma DC. Are intravenous fluids morally required for a dying patient. Arch Intern Med 1983;143:975-8.

2 Tifft S. Debate on the boundary of life. Time 1983 April $11: 68-70$.

${ }^{3}$ Nelson L. Doctors debate right to stop "heroic" effort to keep elderly alive. Wall St fournal 1982 Sept 7;52:1-20.

4 Hilfiker D. Allowing the debilitated to die. N Englf Med 1983;308:716-9.

5 President's Commission for the Study of Ethical Problems in Medicine and Biomedical and Behavioral Research. Deciding to forego life-sustaining treatment. A report on the ethical, medical, and legal issues in treatment decisions. Washington: Superintendent of documents, Government printing office, March 1983.

B Abram MB. Ethics and the new medicine. New York Times Magazine 1983 June 5:68-100. 